\title{
Sustainability Assessment of Bitumen with Polyethylene as Polymer
}

\author{
Tariq Ali ${ }^{1}$, Nouman Iqbal ${ }^{1}$, Dr.Mehboob Ali ${ }^{1}$, Dr. khan shahzada ${ }^{2}$ \\ ${ }^{1}$ (Civil Engineering Department, The University of Lahore, Lahore, Pakistan) \\ ${ }^{2}$ (Civil Engineering Department, University of Engineering and Technology Peshawar, Pakistan)
}

\begin{abstract}
Now a day's increment in percentage of waste material due to excessive use of polyethylene in daily use products has become a great problem. Most of the waste materials are of types which are nonbiodegradable. These materials require difficult and challenging methods to dispose safely and in underdeveloped countries like Pakistan it is even a bigger problem of concern. Also the continuous increase in number of vehicles emphasizes on need of sustainable infrastructure of roads with better quality and engineering design. Grinded plastic is used as polymer in Bitumen in this research by $0 \%, 0.5 \%, 1 \%, 1.5 \%$ and $2 \%$.The properties evaluated are Fire point, Flash point, softening point and penetration of Bitumen. Regardless of the replacement ratio, Bitumen as a polymer had a satisfactory performance.
\end{abstract}

\section{INTRODUCTION}

The continuous increase in number of vehicles emphasizes on need of sustainable infrastructure of roads. Specially in under developed countries like Pakistan where road networks don't get the proper maintenance due to lack of effective machinery and funds , there is a major need of better infrastructure of roads which needs less maintenance and serve the purpose. To abandon the process of deterioration of roads many methods may prove useful, e.g., increasing budget for alimony, better roadway structure, choosing more appropriate components and state of the art technologies used for construction. The pavement structure of roads is basically flexible in Pakistan and its reliability is affected by many important factors, e.g., environmental conditions, chemical and physical properties of materials in mix (additive, binder and aggregate) and the ratio in which these materials are used. The performance of mix (bitumen) can be noticeably enhanced by changing the additive part in the mix. There are currently many additives being used, but polymers are of great interest and a field of research these days.

Another interesting use of polymers is in asphalt concrete amalgamates which in return produces an aggregate covering stuff. These coverings will prove helpful in increasing the surface roughness and hence, show more resistance against wear and more closely meet the modern world requirements.

From the last five decades the population all over the world has increased enormously, and to meet the gap of supply and demand rapid increase in number of industries has become a necessity and as an end result production of by products, mainly waste materials became a great problem. Most of the waste materials are of type which are non-degradable and non-recyclable e.g., Tires, tubes, some form of plastics, ash, slag (Steel and blast furnace), harmful chemicals and toxic resins. These materials require difficult and challenging methods to dispose safety and in underdeveloped countries like Pakistan it is even a bigger problem of concern.

There comes a great need to find out some useful purpose of these thin polythene wrappers as they are abundant as waste materials. If so happens that they find their application, they can be easily collected and separated from other undesirable trash by interested organizations rather to litter in cans or open places.

\section{OBJECTIVES}

The objectives of this project work are as follows:

1. Study the outcome by mixing of low density polythene with HMA (hot mix asphalt).

2. Study the behavior of Bitumen mix using low density polythene and its applicability to suit our local needs under climatic conditions existent in Pakistan.

3. To evaluate the performance of the modified Bitumen Mix using different tests.

4. To figure out the process which is used to mix modifier (polythene) in HMA mix in such a way to produce best physical properties.

5. To evaluate the polythene content to be used in bituminous mixes.

6. Comparative analysis of the bitumen modified mix and conventional HMA.

\section{SCOPE OF PROJECT}

Basic aim of this project is to evaluate the performance of polythene modified bituminous mix and its potential to improve the binding properties of the mix, Marshall stability value, flow, penetration resistance, 
temperature susceptibility and rutting resistance of asphalt concrete wearing course. Also included in the scope of the research is to analyze the economy achieved by this process and its impact on the waste management.

\section{LITERATURE REVIEW}

This section provides a brief description about the major work contribution of the researchers in the field of polymer modified bitumen mix. This work proposes a novel approach for different step towards accomplishing task and the state of the art used. To use waste plastic as modifier, firstly we need to review its different forms and types, and the best material with desirable characteristics will be chosen.

\section{DISPOSAL OF PLASTIC}

The present day disposal of plastic waste, especially Municipal Solid Waste containing plastics, is carried out by:

Land filling

Incineration

Land filling is a process in which the waste materials are buried in a specific area, away from the city. This process is purely temporary. This may result in:

1. Affecting water recharge.

2. Reducing soil microbial activity.

3. Clogging the drainage.

4. Water line clogging.

5. $\quad$ More demand of budget.

Such clogging may result in the production of gases like methane, which affects Green House effect. Above all, land availability for filling is also a problem.

\subsection{Asphalt Cements}

\section{COMPONENT MATERIALS}

This material is present in a wide range of forms like semi-solids, hard solids etc. at acceptable range of temperatures and mainly black in color. When sufficiently heated, it softens and becomes liquid. That process allows the asphalt to coat aggregate particles during the production of hot mix asphalt. Asphalt cement is generally composed of hydrocarbon chains and commonly known as Bitumen mix.

\subsection{Aggregates}

Aggregate forms the major portion of the pavement structure and it is the prime material used in pavement construction. Aggregates constitute a major portion towards load bearing as compared to other mixture materials. It is present in mixtures $91-96 \%$ with respect to mass and $76-86 \%$ w.r.t area.

\subsection{Fillers}

In asphalt mixes, sand is basically used as fillers to compliment other components present in mix. Filler is that portion which passes No. 200 sieve. It may take the form of crushed rock, crushed slag, hydrated lime, etc.

\subsection{Polymer}

There are several kinds of polymers that can be recycled in bitumen. Out of various types, some are used on massive level as, polythene (both less and more dense) mainly find its application in industries for packaging purposes of products. Polypropylene is used for straw making, textile, automobile industries and furniture industries. Polyvinyl chloride makes hard and durable sentry lines and coverings; polythene terephthalate is a major ingredient used in beverages companies, and achrylonitrate butedyne stirene mainly utilized by microtechnology industrial sector.

\section{EXPERIMENTAL DESIGN AND METHODOLOGY}

To find out the optimum polymer content to be used in HMA and carry out a comparative analysis of modified (polymer added HMA) and unmodified (conventional) HMA, an experimental design/methodology was established in this study

\subsection{Penetration Test}

The penetration test determines the hardness or softness of mix, measuring depth up to fraction of millimeter. Some sample of material is placed under marked loaded syringe and penetration test is performed under known specific values of mass, temp etc. Bitumen grade is specified in terms of the penetration value. 
Table 1: Comparison of Percentage of Polymer Added with Penetration Value

\begin{tabular}{|c|c|}
\hline \% of Polymer in Bitumen & Penetration Value \\
\hline $\mathbf{0}$ & 86 \\
\hline $\mathbf{2}$ & 69 \\
\hline $\mathbf{4}$ & 62 \\
\hline $\mathbf{6}$ & 55 \\
\hline $\mathbf{8}$ & 48 \\
\hline $\mathbf{1 0}$ & 37 \\
\hline $\mathbf{1 2}$ & 22 \\
\hline $\mathbf{1 4}$ & Nil \\
\hline
\end{tabular}

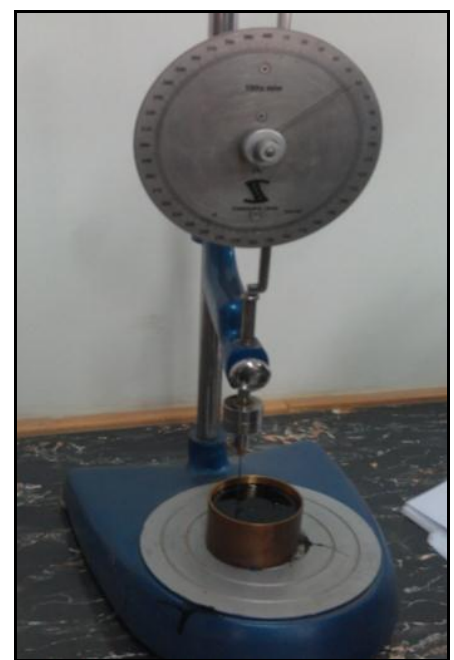

Figure 1: Apparatus for Bitumen Penetration Test

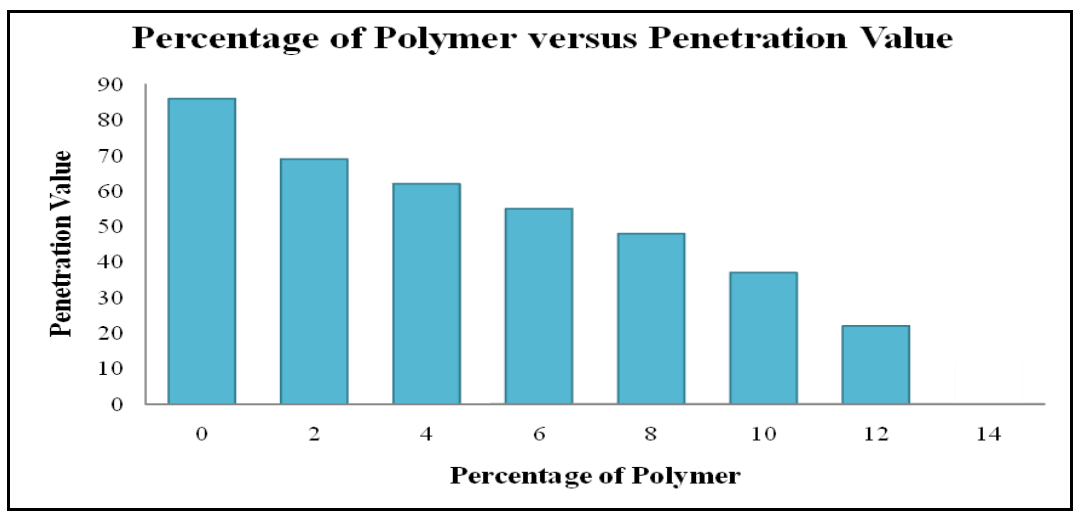

Figure 2: Comparison of Percentage of Polymer Added with Penetration Value

\subsection{Softening Point}

To check the physical reliability of mix, softening point plays an important role, it indicates a certain temperature at which sample under consideration get soften up to a certain level. Ring and bell method is used to evaluate that particular temperature.

Table 2: Comparison of Percentage of Polymer Added with Softening Point

\begin{tabular}{|c|c|}
\hline \% of Polymer in Bitumen & ${\text { Softening Point } \mathbf{C}^{\circ}}^{\circ}$ \\
\hline $\mathbf{0}$ & 56 \\
\hline $\mathbf{0 . 5}$ & 59 \\
\hline 1 & 63 \\
\hline $\mathbf{1 . 5}$ & 66 \\
\hline
\end{tabular}




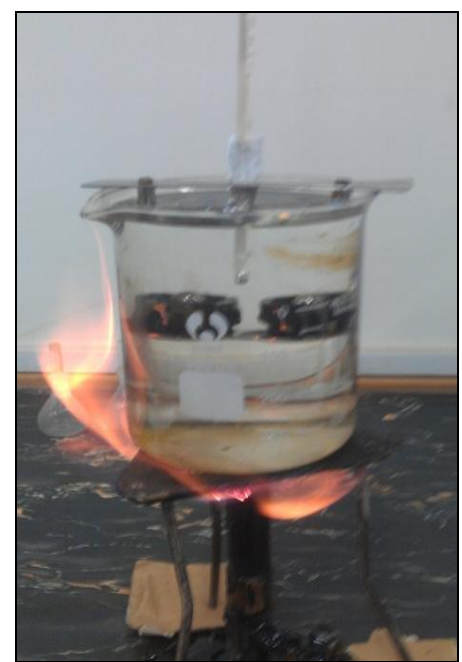

Figure 3: Apparatus for Determining Softening Point of Asphalt

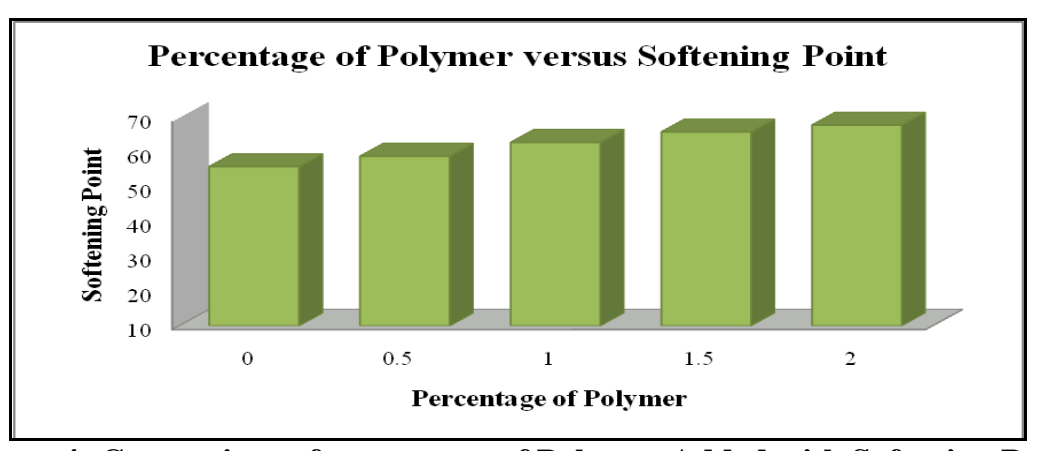

Figure 4: Comparison of percentage of Polymer Added with Softening Point

\subsection{Flash and Fire Point}

Polythene modified bitumen mixes are nearly fire free or when subjected to high temperatures (within a certain limit), don't get burn too easily. At a minimum level of temperature when some material's vapors catch fire like a flash following certain specifications is called flash point of subjected sample. While on the other hand at certain level of temperature when subjected sample catches fire and starts burning following certain specifications is termed as fire point.

Table 3: Comparison of Percentage of Polymer Added with Fire and Flash Point

\begin{tabular}{|c|c|c|}
\hline$\%$ of Polymer in Bitumen & Flash Point $\mathrm{C}^{\circ}$ & Fire Point $\mathrm{C}^{\circ}$ \\
\hline $\mathbf{0}$ & 240 & 250 \\
\hline 0.5 & 245 & 256 \\
\hline 1 & 257 & 270 \\
\hline 1.5 & 263 & 275 \\
\hline 2 & 270 & 280 \\
\hline
\end{tabular}

Figure 5: Apparatus for Determining Flash and Fire Point 


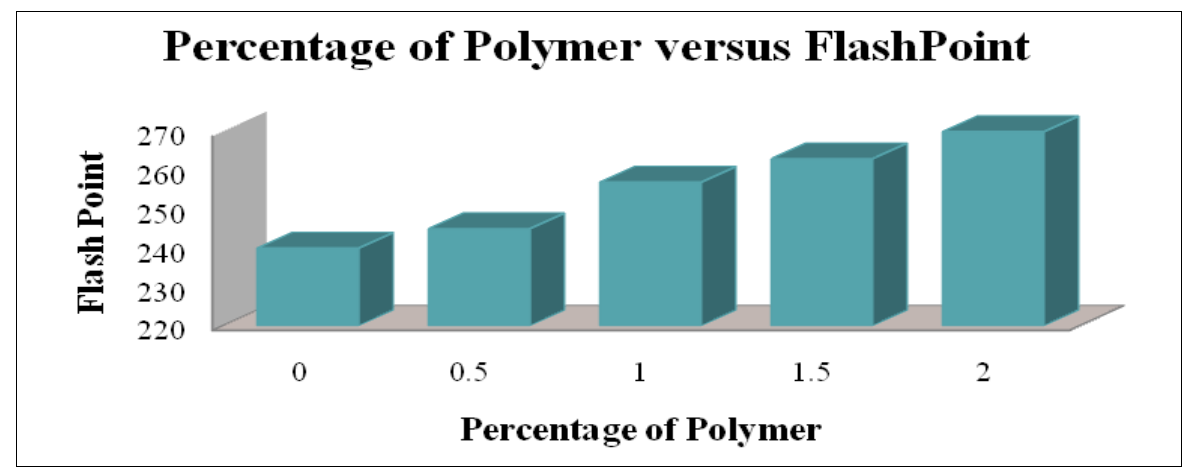

Figure 6: Comparison of Percentage of Polymer Added with Flash Point

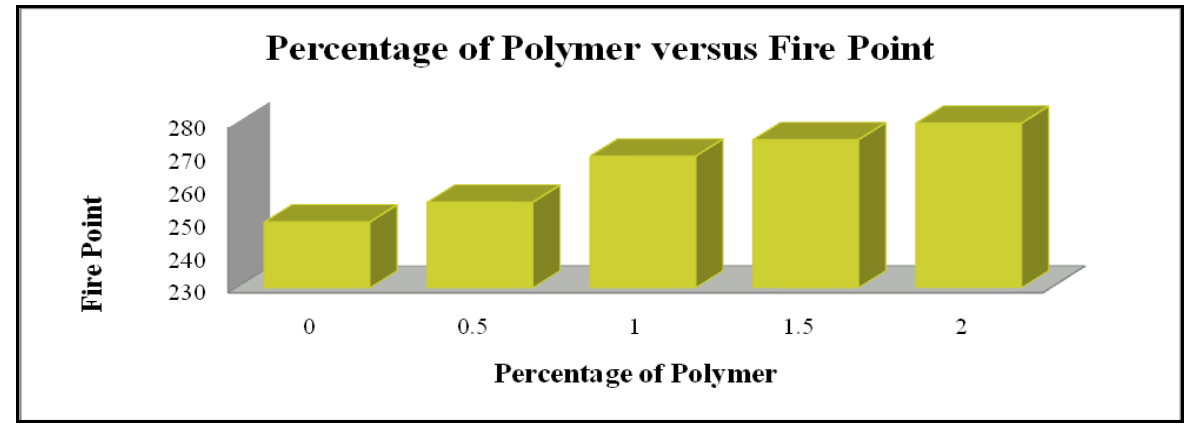

Figure 7: Comparison of Percentage of Polymer Added with Fire Point

\section{CONCLUSIONS}

Polymer modified HMA shows better engineering properties than simple bitumen mix and it has a higher stiffness at high service temperature (summer) that will result in reduced rutting. Asphalt -aggregate bonding is improved which will result in reduce stripping or moisture susceptibility.

The blend has increased softening point. This phenomenon indicates that the resistance of the binder to the effect of heat is increased and it will reduce its tendency to soften in hot weather. Thus, with the addition of polyethylene the modified binder will be less susceptible to temperature changes. The effect of softening point of a binder on resistance to permanent deformation, of bituminous pavement mixes, has been studied by various researchers. An example is hot rolled asphalt where it was found that the rate of rutting in the wheel tracking test at $45^{\circ} \mathrm{C}$, was halved by increasing softening point by approximately $5^{\circ} \mathrm{C}$ (Fernando \& Guirguisl, 1984). Therefore it is expected that by using the polyethylene in the bituminous mix the rate of rutting will decrease due to the increase in softening point.

Polymer modified bitumen mix will tend to increase in the softening point, and this will prove beneficial in the extreme weather conditions like in hot summer days, the bleeding will be less and in rainy season days bleedings accounts for the slippery condition. Blend has decreased grooving rate. Which means by admixture polyethylene makes modified mix harder and more consistent. This is good in the sense that it improves the overall performance of HMA by increased rutting resistance, durability, and load carrying capacity, improved resistance to weathering effects, increased stability and improved binding properties of HMA. The adhesion between aggregate and asphalt binder is increased by coating polyethylene on aggregates which helps to reduce stripping.

\section{RECOMMENDATIONS}

There are many things which can be done in proper utilization of waste byproducts in future. A lot of work can be done to facilitate traffic loads with better pavements and long lasting lives. Proper data record of availability of thin polythene waste in rural and urban areas and percentage of elements of interest present in it. Exploring new methods to collect waste plastic materials and separate them from unwanted elements.

Implanting new techniques which are most efficient and cost reductive, to transform waste plastic products into useable form to be used as modifiers for bitumen and asphalt mixes. Involvement of more concerned business class or entrepreneurs who could establish new plants within bitumen boiler for proper mixing of cleaned and modified plastic waste as additives with bitumen blends. Polymer modified HMA (hot mix asphalt) pavements should be tested under different possible 
conditions to produce best reliability results and field surveys should be conducted to produce further improvements.

\section{REFERENCES}

[1]. Subagio, B.S., et al., 2005. Development of stiffness modulus and plastic deformation characteristics of porous asphalt mixture using tafpack super, Proceed. Eastern Asia Soc. Transportation Studies, 5: 803 - 812

[2]. Saez-alvan, L.D.P, et al., 2003. Mechanical behavior of asphalt mixtures in regions of low temperature and altitude above 3800 meters, 2003 Int. Conf. Airports: Planning, Infrastructure \& Environ. Rio De Janeiro - RJ-Brazil - June 8 - 11.

[3]. Catt, O.V., 2004. Investigation of polymer modified asphalt by shear and tensile compliances. Material Characterization for Inputs into AASHTO 2002 Guide Session of the 2004 Annual Conf. Transportation Assoc. Canada, Québec City, Québec.

[4]. Coplantz, J.S. et al., 1993. Review of relationships between modified asphalt properties and pavement performance. SHRP-A-631, Strategic Highway Res. Program, National Res. Council Washington, USA.

[5]. Newman, K., 2004. Polymer-modified asphalt mixtures for heavy-duty pavements: fatigue characteristics as measured by flexural beam testing, 2004 FAA Worldwide Airport Technol. Transfer Conf. Atlantic City, New Jersey, USA 